\title{
Detecção imunoistoquímica de receptores de estrógeno e progesterona no endométrio de vacas Nelore (Bos taurus indicus) durante o anestro pós-parto
}

\author{
[Immunohistochemical detection of receptors for estrogen and progesterone in endometrial glands and stroma \\ during the pospartum anestrus in Nelore (Bos taurus indicus) cows] \\ R.S. Lima, I. Martin, W.C. Marques Filho, M.M.P. Rodrigues, \\ R. Laufer-Amorim, J.C.P. Ferreira*
}

Faculdade de Medicina Veterinária e Zootecnia - Universidade Estadual Paulista

Distr. Rubião Jr, s/n

18.618-000 - Botucatu, SP

\begin{abstract}
RESUMO
Foram utilizadas 24 vacas Nelore P.O., em anestro pós-parto, diagnosticado pelo histórico reprodutivo, por avaliações ultrassonográficas transretais e por dosagem de progesterona plasmática, que foram submetidas à colheita de fragmento uterino via transcervical. Os animais foram divididos em dois grupos conforme o máximo diâmetro folicular: grupo 1: folículos $<6 \mathrm{~mm}(\mathrm{n}=12)$; grupo 2: folículos $\geq 6 \mathrm{~mm}(\mathrm{n}=12)$. Para avaliar receptor de estrógeno e receptor de progesterona no epitélio glandular e no estroma, foi utilizada a técnica de imunoistoquímica. Altas contagens relativas e alta intensidade de marcação para receptor de estrógeno e progesterona no epitélio glandular e no estroma foram observadas nos dois grupos. No entanto, a intensidade de marcação para o receptor de progesterona no epitélio glandular foi mais alta no grupo 2 comparado ao grupo 1. Quando o epitélio glandular e o estroma foram comparados, o número relativo de receptor de estrógeno no grupo 1 foi mais alto no epitélio glandular comparado ao estroma, e a intensidade de marcação para o receptor de progesterona no grupo 2 foi mais alta no epitélio glandular comparado ao estroma. Os resultados sugerem que os mecanismos que controlam a expressão de receptores no anestro são semelhantes aos observados durante o ciclo estral.
\end{abstract}

Palavras-chaves: Nelore, endométrio, receptores esteroidais

\begin{abstract}
Twenty-four postpartum anestrous Nelore purebred cows were used in the study. Anestrous was determined based on the reproductive history which was confirmed in each cow based on plasma progesterone concentration and by transrectal ultrasonography. Endometrial biopsies were collected. The animals were separated into two groups according to maximum follicular diameter-Group 1: follicles $<6 \mathrm{~mm}(n=12)$ and Group 2: follicles $\geq-6 \mathrm{~mm}$ follicles $(n=12)$. The immunohistochemistry technique was employed to evaluate the presence of estrogen and progesterone receptors in the uterine glandular epithelium and stroma. High counts of positive nuclei and high intensity of immunostain for estrogen and progesterone receptors in the glandular epithelium and stroma were observed in the two groups. However, the immunostain intensity of progesterone receptors in the glandular epithelium was higher in Group 2 compared to Group 1. When glandular epithelium and stroma were compared within each group, the relative number of estrogen receptors in the Group 1 was higher in the glandular epithelium compared to stroma and the immunostain intensity for the progesterone receptor in Group 2 was higher in the glandular epithelium compared to stroma. The results suggest that the mechanisms that control the expression of endomerial receptors in the anestrus are similar to the ones observed during the estrus cycle.
\end{abstract}

Keywords: Nelore, endometrium, steroidal receptor

Recebido em 28 de janeiro de 2011

Aceito em 8 de junho de 2011

*Autor para correspondência (corresponding author)

E-mail: jcferreira@fmvz.unesp.br 


\section{INTRODUÇÃO}

Em bovinos Bos taurus taurus, a concentração de receptores endometriais de estrógeno (RE) modifica-se ao longo do ciclo estral, sendo maior durante o proestro e estro que durante a fase luteal média (dias nove a 14) (Henricks e Harris, 1978; Boos et al. 1996; Robinson et al., 2001). Esse mesmo comportamento foi observado em animais Bos taurus indicus da raça Nelore (Martin et al., 2008).

Os receptores endometriais de progesterona (RP) apresentaram a mesma dinâmica de modificação ao longo do ciclo estral observada para os RE (Boos et al., 1996, Robinson et al., 2001, Martin et al., 2008).

O mesmo padrão de aumento ou diminuição observado na concentração dos RE e RP endometriais foi também encontrado na expressão do RNAm para esses receptores (Robinson et al., 2001), sugerindo a existência de mecanismos de regulação dos RE e RP endometriais que envolvem os próprios hormônios, pois o aumento da concentração de RE e RP endometriais acontece simultaneamente com a elevação da concentração plasmática e tecidual de estrógeno (E), e está também relacionado com a diminuição da concentração plasmática de progesterona $\left(\mathrm{P}_{4}\right)$. Por outro lado, prolongada exposição às elevadas concentrações de $\mathrm{P}_{4}$ que ocorre durante $\mathrm{o}$ diestro promove efeito inibitório na concentração desses receptores.

Essa hipótese foi comprovada in vitro por Xiao e Goff (1999), que demonstraram que o $\mathrm{E}$ ocasionou aumento da concentração do seu próprio receptor e do RP no epitélio e no estroma endometrial, enquanto a $\mathrm{P}_{4}$ não apresentou efeito similar, mas inibiu os efeitos do E na indução do aumento do número de RP. Foi ainda observado que a $\mathrm{P}_{4}$ não inibiu a ação estimulatória do $\mathrm{E}$ sobre o próprio $\mathrm{RE}$ nas células epiteliais, demonstrando uma diferença na regulação do receptor entre os tipos celulares.

O anestro pós-parto, período que vai do parto até a manifestação do primeiro cio fértil (Yavas e Walton, 2000), tem sua duração influenciada por diversos fatores, sendo os de maior importância a nutrição e a amamentação. É um período de transição no qual o eixo hipotalâmico- hipofisiário-ovariano-uterino se recupera do período gestacional (Short et al., 1990). Nos últimos 22 dias de gestação, a retroalimentação negativa causada pela $\mathrm{P}_{4}$ de origem luteínica e $\mathrm{E}$ de origem placentária suprime o aumento episódico do hormônio folículo estimulante (FSH), fazendo com que os ovários, durante os últimos 20 a 25 dias de gestação, mantenham-se quiescentes.

No parto, com a regressão do corpo lúteo (CL) e expulsão da placenta, as concentrações circulantes de $\mathrm{P}_{4}$ e $\mathrm{E}$ diminuem agudamente (Perry et al., 1991, Crowe, 2008). As concentrações plasmáticas de $\mathrm{E}$ só se restabelecem por volta do nono dia do puerpério, devido à emergência da primeira onda de desenvolvimento folicular consequente ao restabelecimento da secreção hipofisária de FSH que acontece entre o terceiro e o quinto dia pósparto (Yavas e Walton, 2000, Crowe, 2008,). Porém, a concentração de E é baixa comparada aos valores encontrados no plasma (Garverick $e t$ al., 1988) e no fluído folicular (Braden et al., 1989) durante o ciclo estral, principalmente no período preovulatório. Foi observado por Borges et al. (2004) uma média de cinco (4-8) ondas foliculares em vacas da raça Gir entre quatro e 50 dias pós-parto, sendo o diâmetro máximo dos folículos dominantes para as diversas ondas, em média, 8,9mm (6,6-12,2mm). Crowe (2008) verificou que vacas de corte, em boa condição corporal, ovulam o primeiro folículo dominante

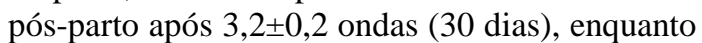
para vacas em má condição corporal são necessárias $10,6 \pm 1,2$ ondas de crescimento folicular antes que a ovulação ocorra (70-100 dias). A maturação do folículo dominante desta primeira onda folicular e o seu destino dependem do aumento da frequência dos pulsos de hormônio luteinizante (LH), e isso irá aumentar a capacidade do folículo para secretar E e induzir a retroalimentação positiva sobre o hormônio liberador de gonadotrofina $(\mathrm{GnRH})$, resultando em seu pico e consequente ovulação (Crowe, 2008).

Este estudo teve por objetivo avaliar, por meio da técnica de imunoistoquímica, a expressão de receptores endometriais de $\mathrm{E} \mathrm{e}_{4}$ em vacas Nelore durante o anestro puerperal, considerando que não existem estudos a respeito do comportamento desses receptores durante $\mathrm{o}$ anestro pós-parto na raça Nelore. 


\section{MATERIAL E MÉTODO}

Foram utilizadas 24 vacas Nelore PO (Protocolo de aprovação do Comitê de Ética $n^{\circ}$ 77/2007CEEA), em anestro pós-parto, adultas, provenientes do rebanho da Fazenda Experimental São Manuel da Faculdade de Medicina Veterinária e Zootecnia - Unesp, Campus de Botucatu, localizada no município de São Manuel, estado de São Paulo. Os animais foram mantidos em regime de pastejo recebendo sal mineral e água ad libitum.

O anestro pós-parto foi confirmado pelo histórico reprodutivo, ausência de CL constatada por meio de palpação e ultrassonografia (Aloka SSD 500 com transdutor de 5,0 MHz) ovarianas transretais e dosagem de $\mathrm{P}_{4}(<1 \mathrm{ng} / \mathrm{mL})$.

No momento da avaliação ultrassonográfica, uma vez determinada a ausência do CL, foram também mensurados e registrados os folículos ovarianos.

O grau de desenvolvimento folicular observado foi confrontado com os resultados observados por Sartorelli et al. (2005), que, estudando a dinâmica folicular de vacas Nelore, encontraram que a emergência da onda folicular foi detectada quando os folículos alcançavam o diâmetro médio de 4,3mm, e o desvio quando o maior folículo da onda alcançava diâmetro médio de $6,1 \mathrm{~mm}$. Os animais foram divididos em dois grupos, conforme o grau de desenvolvimento folicular:

grupo 1 (pré-desvio) - formado por animais portadores de folículos $<6,0 \mathrm{~mm}(\mathrm{n}=12)$; grupo 2 (pós-desvio) - formado por animais portadores de folículos de diâmetro $\geq 6,0 \mathrm{~mm}(\mathrm{n}=12)$.

Após a classificação dos animais, foi realizada a limpeza da região perineal e vulvar com papel toalha, e colhida, por acesso transcervical, uma amostra endometrial de cada fêmea com o emprego de pinça de biopsia estéril do tipo Yomann (Hauptner, Solingen, Germany). O fragmento obtido foi retirado da pinça com auxílio de uma agulha hipodérmica, lavado em solução fisiológica e acondicionado em cassete plástico para inclusão histológica em parafina.
Após a obtenção do fragmento endometrial, uma amostra de sangue da veia jugular foi colhida, centrifugada a 2500 x g por 15 minutos, e o plasma obtido armazenado a $-20^{\circ} \mathrm{C}$.

Posteriormente, foi determinada, por radioimunoensaio, a concentração plasmática de $\mathrm{P}_{4}$ empregando-se kits comerciais em fase sólida (DPC, Los Angeles, CA, USA), seguindo-se as instruções do fabricante.

Os fragmentos endometriais foram fixados em formol tamponado $10 \%$ durante 24 horas e, posteriormente, mantidos em álcool $70 \%$ até o momento de inclusão em parafina. Foram, então, obtidos cortes histológicos de $3 \mu \mathrm{m}$ estendidos em lâminas com extremidade fosca previamente tratadas com organosilano (3-Aminopropyl Triethoxy-silane, Sigma - Aldrich, São Paulo SP, Brasil. Cód A3648).

Para a desparafinização do material emblocado, as lâminas foram colocadas em cuba de vidro com xilol à temperatura ambiente e, posteriormente, passaram por um processo de desidratação em banhos de álcool.

A etapa seguinte constituiu-se na recuperação antigênica realizada em solução de citrato de sódio $10 \mathrm{mM}$ e pH 6,0, com incubação em micro-ondas, potência máxima $-750 \mathrm{~W}$, durante 15 minutos (três ciclos de cinco minutos cada). Posteriormente, foi feita a lavagem em água destilada. Após o resfriamento da solução por 20 minutos à temperatura ambiente, as lâminas foram lavadas em dez banhos de água destilada.

Logo após, foi realizado o bloqueio da peroxidase endógena em solução de água oxigenada $8 \%$ ( $8 \mathrm{~mL}$ de água oxigenada e $92 \mathrm{~mL}$ de metanol) por dois períodos de 10 minutos trocando-se a solução a cada período. O material foi, então, submetido a 10 lavagens em água destilada e, a seguir, duas lavagens em solução tampão TRIS (pH 7,4) de cinco minutos cada.

Realizou-se, então, a incubação com o anticorpo primário. Para a detecção de receptores de progesterona (isoformas A e B), foi utilizado um anticorpo monoclonal obtido em camundongo antirreceptor de progesterona (Monoclonal Mouse Anti-Human Progesterone Receptor Ab-8 (Clone hPRa 2+ hPRa 3) - Thermo Fisher Scientific - CA, USA) humano; para a detecção 
de receptores de estrógeno tipo $\alpha$, foi utilizado um anticorpo monoclonal obtido em camundongo antirreceptor de estrógeno $\alpha$ (Monoclonal Mouse Anti-Human Estrogen Receptor $\alpha$ clone 1D5 - DakoCytomation - CA, USA. Cód M7047) humano. Ambos os anticorpos foram diluídos com o diluente de anticorpo (Antibody Diluent with Background Reducing Components - DakoCytomation - CA, USA. Cód S3022) na concentração de 1:50. A solução contendo o anticorpo foi uniformemente distribuída por toda a superfície do corte, e as lâminas foram incubadas em câmara úmida, durante 18 horas, à temperatura de $4^{\circ} \mathrm{C}$.

Posteriormente, foi realizada a lavagem com solução tampão TRIS e incubação com anticorpo secundário ligado à peroxidase $\left(\right.$ EnVision $^{\circledR}$ EnVision DualLink - DakoCytomation - CA, USA. Cód K4061) por 60 minutos. Realizaramse nova lavagem com solução tampão TRIS e revelação com cromógeno DAB (3,3'diaminobenzidina - Liquid DAB Cromogen ${ }^{\circledR}$ DakoCytomation - CA, USA. Cód K3468) durante cinco minutos ao abrigo da luz. A reação foi interrompida com a lavagem em solução tampão TRIS.

As lâminas foram contracoradas com Hematoxilina de Harris por três minutos, sendo a coloração interrompida com a lavagem em água corrente por 10 minutos. Após desidratação, as lâminas foram montadas com lamínulas utilizando-se resina sintética - Permount (Fisher Scientific - Cód. UN1294) e avaliadas quanto à imunomarcação em microscópio óptico (Leica Microsystems - DMLB - Germany) em aumento de 400X, adaptado a uma câmera Leica DFC 500 (Leica Microsystems - DMLB - Germany) com um analisador de imagens (Leica Q500IW), utilizando-se o programa Leica QWin Standard V2.5.

A leitura das lâminas foi realizada sob microscopia óptica em aumento de 400X, utilizando-se dois métodos. No primeiro, foi realizada a contagem do número de núcleos positivos (marrons), independente da intensidade de marcação, e negativos (azuis), até que a contagem alcançasse a soma de 400 núcleos no epitélio glandular e 200 no estroma uterino. A outra avaliação utilizada foi um sistema de escore para codificar a intensidade de imunomarcação. Escore 1 representava $\leq 25 \%$ de núcleos fortemente corados; escore 2, >25 a $\leq 50 \%$; escore $3,>50$ a $\leq 75 \%$; e escore $4, \geq 75 \%$. Como controle negativo, foi empregada a substituição do anticorpo primário pela imunoglobulina de camundongo mantendo-se idênticas as demais etapas da reação.

Para todas as variáveis, foram empregados a média como medida de tendência central e o desvio-padrão para representar a variabilidade dos dados (Curi, 1997). A comparação entre os grupos experimentais foi realizada pelo teste de $t$ de Student a 5\% de probabilidade (BioEstat 5.0).

\section{RESULTADOS}

A técnica de colheita de amostras endometriais empregada foi adequada para a obtenção de fragmentos de aproximadamente $4 \mathrm{~mm}$ de diâmetro. Contudo, das 24 amostras obtidas, 10 foram excluídas por terem sido obtidas de animais que, a despeito da ausência de CL na ultrassonografia, apresentaram concentração plasmática de $\mathrm{P}_{4}$ acima de $1 \mathrm{ng} / \mathrm{mL}$.

As 14 amostras restantes, em função do desenvolvimento folicular dos animais, foram alocadas nos grupos 1 e 2, formados por sete amostras cada.

As contagens relativas de $R P$ e RE no endométrio não diferiram quando comparado os grupos estudados (grupo 1 e grupo 2), tanto no estroma quanto no epitélio glandular $(\mathrm{P} \geq 0,1-$ Tab. 1 e 2 - Fig. 1 e 2).

Quando os tecidos foram comparados, epitélio glandular com estroma, nos mesmos grupos de desenvolvimento folicular, o grupo 1 apresentou maior contagem relativa no epitélio glandular quando comparado ao estroma para $\mathrm{RE}(\mathrm{P}=0,01$ - Fig. 2), porém não houve diferença no grupo 2 para RE $(\mathrm{P}>0,2)$. Quando a marcação relativa de $\mathrm{RP}$ foi comparada entre epitélio glandular e estroma, não houve diferença entre os tecidos tanto para o grupo 1 quanto para o grupo 2 (P>0,3 - Fig. 1).

Quando comparados os grupos, a intensidade de marcação de RP no epitélio glandular aumentou do grupo 1 para o grupo $2(\mathrm{P}=0,03)$. Não houve diferença de intensidade de marcação para RE no epitélio glandular $(\mathrm{P} \geq 0,06)$ e no estroma $(\mathrm{P} \geq$ $0,1)$. 
Quando epitélio glandular e estroma foram comparados, o epitélio glandular apresentou maior intensidade de marcação quando comparado ao estroma no grupo 2 para $\mathrm{RP}(\mathrm{P}=$
0,03). Não houve diferença de intensidade de marcação para $\mathrm{RE}$ para o grupo $1(\mathrm{P} \geq 0,5) \mathrm{e}$ grupo $2(\mathrm{P} \geq 0,3)$.

Tabela 1. Valores médios (desvio-padrão) para contagem relativa (\%) e intensidade de marcação dos núcleos positivos para receptores endometriais de progesterona no epitélio glandular e estroma de vacas Nelore em anestro, segundo o diâmetro folicular (G1: folículos $<6,0 \mathrm{~mm}$; G2: folículos $\geq 6,0 \mathrm{~mm}$ )

\begin{tabular}{lcccc}
\hline \multirow{2}{*}{ Grupo } & \multicolumn{2}{c}{ Epitélio glandular } & \multicolumn{2}{c}{ Estroma } \\
\cline { 2 - 5 } & Núcleos positivos & $\begin{array}{c}\text { Intensidade de } \\
\text { marcação }\end{array}$ & Núcleos positivos & $\begin{array}{c}\text { Intensidade de } \\
\text { marcação }\end{array}$ \\
\hline G1 $(\mathrm{n}=7)$ & $83,7(8,9) \mathrm{aA}$ & $2,7(1,0) \mathrm{aA}$ & $84,9(7,9) \mathrm{aA}$ & $3,1(0,4) \mathrm{aA}$ \\
$\mathrm{G} 2(\mathrm{n}=7)$ & $88,1(6,5) \mathrm{aA}$ & $3,6(0,5) \mathrm{bA}$ & $85,4(8,9) \mathrm{aA}$ & $3(0) \mathrm{aB}$ \\
\hline
\end{tabular}

Letras minúsculas diferentes na mesma coluna $(\mathrm{P}<0,05)$.

Letras maiúsculas diferentes na mesma linha $(\mathrm{P}<0,05)$.

Tabela 2. Valores médios (desvios-padrão) para contagem relativa (\%) e intensidade de marcação dos núcleos positivos para receptores endometriais de estrógeno no epitélio glandular e estroma de vacas Nelore em anestro, segundo o diâmetro folicular (G1: folículos $<6,0 \mathrm{~mm}$; G2: folículos $\geq 6,0 \mathrm{~mm}$ )

\begin{tabular}{lcccc}
\hline \multirow{2}{*}{ Grupo } & \multicolumn{2}{c}{ Epitélio glandular } & \multicolumn{2}{c}{ Estroma } \\
\cline { 2 - 5 } & Núcleos positivos & $\begin{array}{c}\text { Intensidade de } \\
\text { marcação }\end{array}$ & Núcleos positivos & $\begin{array}{c}\text { Intensidade de } \\
\text { marcação }\end{array}$ \\
\hline G1 $(\mathrm{n}=7)$ & $88,1(3,6) \mathrm{aA}$ & $3,3(0,5) \mathrm{aA}$ & $80,5(7,4) \mathrm{aB}$ & $3,1(0,4) \mathrm{aA}$ \\
$\mathrm{G} 2(\mathrm{n}=7)$ & $87,2(11,3) \mathrm{aA}$ & $3,7(0,5) \mathrm{aA}$ & $84,1(7,7) \mathrm{aA}$ & $3,4(0,5) \mathrm{aA}$ \\
\hline
\end{tabular}

Letras minúsculas diferentes na mesma coluna $(\mathrm{P}<0,05)$.

Letras maiúsculas diferentes na mesma linha $(\mathrm{P}<0,05)$.

\section{DISCUSSÃO}

Apesar de só terem sido colhidas amostras endometriais de animais que não apresentavam imagem ultrassonográfica ovariana sugestiva da presença de CL, 41,7\% (10/24) das amostras foram excluídas porque os animais, no momento da colheita, apresentavam concentração plasmática de $\mathrm{P}_{4}$ acima de $1 \mathrm{ng} / \mathrm{mL}$.

A caracterização ultrassonográfica do CL de animais Bos taurus taurus foi descrita por Pierson e Ginther (1984, 1987), Kastelic et al. (1990) e Pieterse et al. (1990). Apesar de Kastelic et al. (1990) terem verificado que $73 \%$ dos CL já podiam ser observados no dia da detecção da ovulação, Pieterse et al. (1990) verificaram que a ultrassonografia transretal era inacurada para a detecção de CL jovens (de um a quatro dias) ou em regressão (17 a 21 dias).

No presente estudo, a elevada proporção de animas com concentração plasmática de $\mathrm{P}_{4}$ acima de $1 \mathrm{ng} / \mathrm{mL}$, a despeito da ausência de CL, provavelmente está relacionada à dificuldade ultrassonográfica de observação luteínica descrita por Pieterse et al. (1990), demonstrando que a caracterização do anestro baseado apenas no histórico de parição recente e ausência do CL é inadequada, havendo a necessidade da determinação concomitante da concentração plasmática de $\mathrm{P}_{4}$.

A técnica imunoistoquímica empregada possibilitou marcar os núcleos positivos para os RE e RP. Por ser uma técnica semiquantitativa, a presença e a intensidade da marcação refletem, respectivamente, a positividade da célula e a concentração destes receptores (Martin et al., 2008). Neste estudo, optou-se pela realização de duas avaliações: contagem de núcleos positivos e negativos e escore representativo da porcentagem de núcleos fortemente marcados.

A intensidade de marcação (núcleos fortemente marcados) para os RE e RP endometriais no estroma e epitélio glandular apresentaram-se elevados em todos os grupos estudados $(>2,7)$. 


\section{Lima et al.}

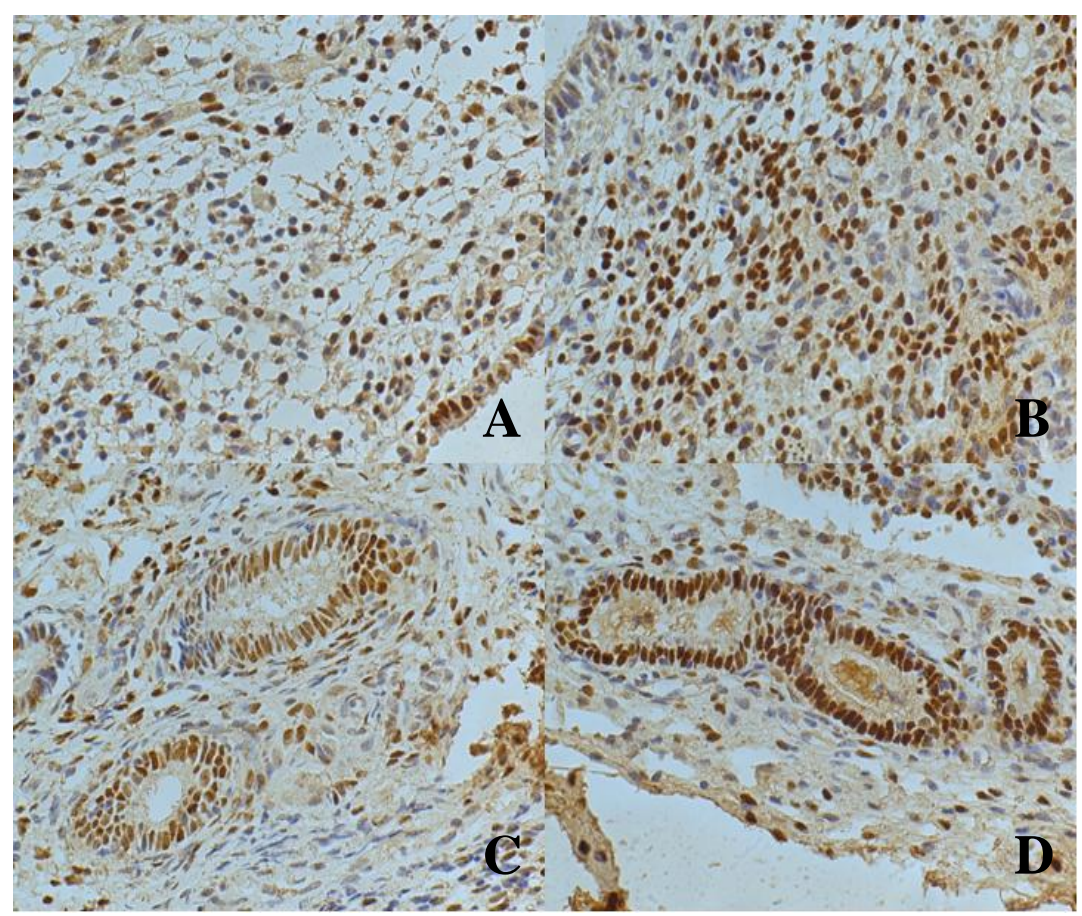

Figura 1. Marcação imunoistoquímica de receptores endometriais de progesterona de vacas Nelore, segundo o diâmetro folicular (aumento: 400x): (A) G1, estroma; (B) G2, estroma; (C) G1, epitélio glandular; (D) G2, epitélio glandular (G1: folículos <6,0mm; G2: folículos $\geq 6,0 \mathrm{~mm}$ ).

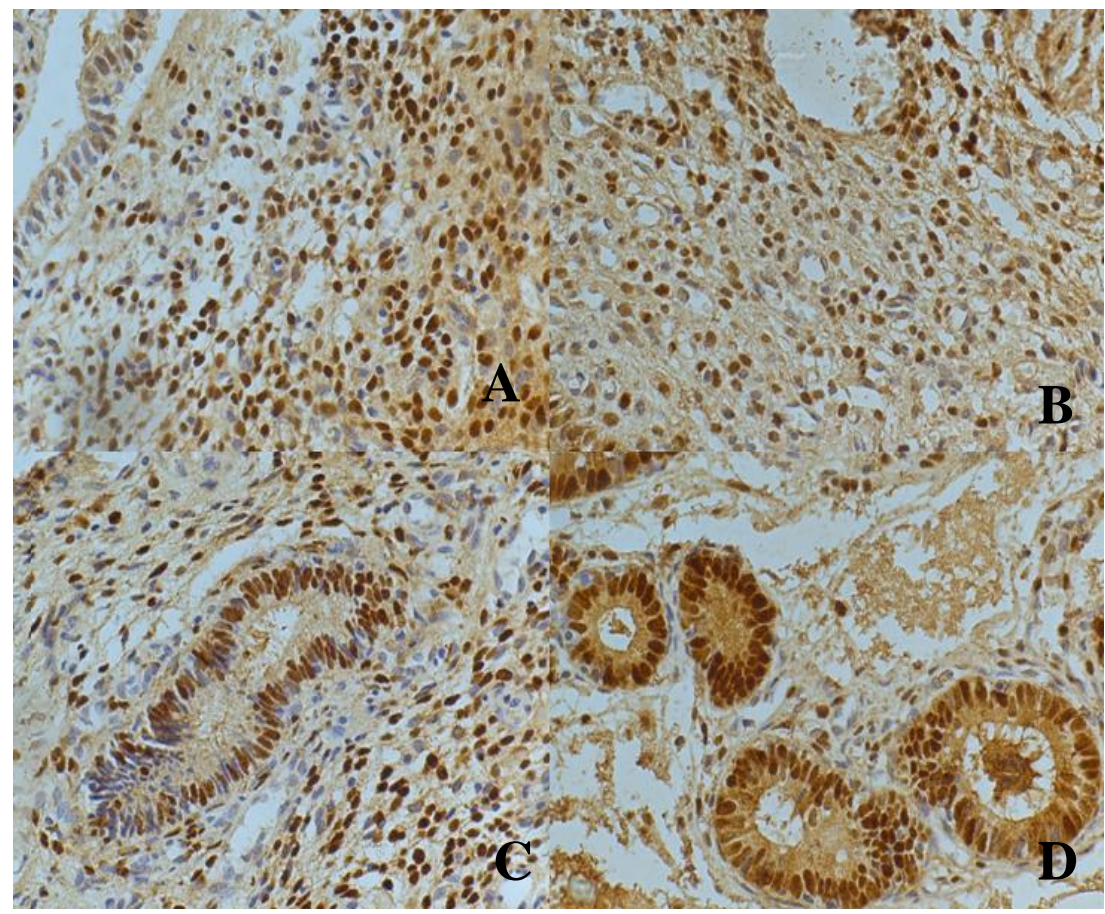

Figura 2. Marcação imunoistoquímica de receptores endometriais de estrógeno de vacas Nelore, segundo o diâmetro folicular (aumento: 400x): (A) G1, estroma; (B) G2, estroma; (C) G1, epitélio glandular; (D) $\mathrm{G} 2$, epitélio glandular (G1: folículos $<6,0 \mathrm{~mm}$; G2: folículos $\geq 6,0 \mathrm{~mm})$. 
Esses resultados sugerem que os mecanismos que controlam a expressão dos receptores esteróides no anestro são semelhantes aos observados durante o ciclo estral, no qual o $\mathrm{E}$ estimula e a $\mathrm{P}_{4}$ deprime a sua expressão (Martin et al., 2008; Robinson et al., 2001). Durante o anestro puerperal, as concentrações de $\mathrm{P}_{4}$ são insignificantes e as de $E$ variáveis, na dependência do grau de desenvolvimento folicular. A despeito dos relatos de que os folículos que se desenvolvem durante o anestro têm menor capacidade esteroidogênica (Garverick et al., 1988; Braden et al., 1989), essa produção foi aparentemente suficiente para que a expressão dos receptores nos dois tecidos endometriais alcançassem concentrações semelhantes às observadas durante as fases folicular e luteínica inicial em animais apresentando ciclos estrais regulares. Como não havia disponibilidade plasmática de $\mathrm{P}_{4}$, a expressão dos receptores manteve-se sempre elevada.

\section{CONCLUSÃO}

Conclui-se que, após o restabelecimento do desenvolvimento folicular durante o anestro pósparto, a produção de E é suficiente para estimular a expressão de receptores endometriais em condições semelhantes às observadas durante o ciclo estral.

\section{AGRADECIMENTOS}

FAPESP - Processo número: 2007/03778-1; auxílio: 2008/052253-6. Fundunesp, Fazenda Experimental São Manuel e Sr. João Ratti Júnior.

\section{REFERÊNCIAS BIBLIOGRÁFICAS}

BIOESTAT 5.0. Download de Arquivos.

Disponível em:

http://www.mamiraua.org.br/download/index.ph p?dirpath=./BioEstat\%205\%20Portugues\&order $=0$. Acesso em: 20 jun 2009 .

BOOS, A.; MEYER, W.; SCHWARZ, R.; GRUNERT, E. Immunohistochemical assessment of oestrogen receptor and progesterone receptor distribution in biopsy samples of the bovine endometrium collected throughout the oestrous cycle. Anim. Reprod. Science, v.44, p.11-21, 1996.
BORGES, A.M.; TORRES, C.A.A.; ROCHA JÚNIOR, V.R. et al. Desenvolvimento folicular no pós-parto de vacas da raça Gir tratadas com Acetato de Buserelina (GnRH) ou Gonadotrofina coriônica humana (hCG). Rev. Bras. Zootec., v.33, p.1396-1404, 2004.

BRADEN, T.D.; KING, M.E.; ODDE, K.G.; NISWENDER, G.D. Development of preovulatory follicles expected to form shortlived corpora lutea in beef cows. J. Reprod. Fertil., v.85, p.97-104, 1989.

CROWE, M.A. Resumption of ovarian cyclicity in post-partum beef and dairy cows: review article. Reprod. Dom. Anim., v.43, suppl.5, p.2028, 2008.

CURI, P.R. Metodologia e Análises da Pesquisa em Ciências Biológicas. Botucatu, Tipomic, 1997, p.263.

GARVERICK, H.A.; PARFET, J.R.; LEE, C.N. et al. Relationship of pre and post-ovulatory gonadotropin concentrations to subnormal luteal function in postpartum beef cattle. J. Anim. Scie., v.66, p.104-111, 1988.

HENRICKS, D.M.; HARRIS, R.B. Cytoplasmatic estrogen receptor and estrogen concentrations in bovine uterine endometrium. Endocrinology, v.103, p.176-85, 1978.

KASTELIC, J.P.; PIERSON, R.A.; GINTHER, O.J. Ultrasonic morphology of corpora lutea and central luteal cavities during the estrous cycle and early pregnancy in heifers. Theriogenology, v.34, p. 487-498, 1990.

MARTIN, I.; TORRES NETO, R.; OBA, E. et al. Immunohistochemical detection of receptors for oestrogen and progesterone in endometrial glands and stroma during the oestrous cycle in Nelore (Bos taurus indicus) cows. Reprod. Dom. Anim., v.43, p.415-421, 2008.

PERRY, R.C.; CORAH, L.R.; KIRACOFE, G.H. et al. Endocrine changes and ultrasonography of ovaries in sucked beef cows during resumption of postpartum estrous cycles. J. Anim. Sci., v.69, p.2548-2555, 1991.

PIERSON, R.A.; GINTHER, O.J. Ultrasonography of the bovine ovary. Theriogenology, v.21, p.495-504, 1984. 
PIERSON, R.A.; GINTHER, O.J. Reliability of diagnostic ultrasonography for identification and measurement of follicles and detecting the corpus luteum. Theriogenology, v.28, p.929-936, 1987.

PIETERSE, M.C.; TAVEME, M.A.M.; KRUIP, T.A.M.; WILLEMSE, A.H. Detection of corpora lutea and follicles in cows: a comparison of transvaginal ultrasonography and rectal palpation. Vet. Rec., v.126, p.552-554, 1990.

ROBINSON, R.S.; MANN, G.E.; LAMMING, G.E.; WATHES, D.C. Expression of oxytocin, oestrogen and progesterone receptors in uterine biopsy samples throughout the oestrous cycle and early pregnancy in cows. J. Reprod. Fertil., v.122, p.965-979, 2001.
SARTORELLI, E.S.; CARVALHO, L.M.; BERGFELT, D.R. et al. Morphological characterization of follicle deviation in Nelore (Bos indicus) heifers and cows. Theriogenology, v.63, p.2382-2394, 2005.

SHORT, R.E.; BELLOWS, R.A.; STAIGMILLER, R.B. et al. Physiological mechanisms controlling anestrus and infertility in postpartum beef cattle. J. Anim. Scie., v.68, p.799-816, 1990.

XIAO, C.W.; GOFF, A.K. Hormonal regulation of oestrogen and progesterone receptors in cultured bovine endometrial cells. J. Reprod. Fertil., v.115, p.101-9, 1999.

YAVAS, Y.; WALTON, J.S. Postpartum acyclicity in suckled beef cows: a review. Theriogenology, v.54, p.25-55, 2000. 